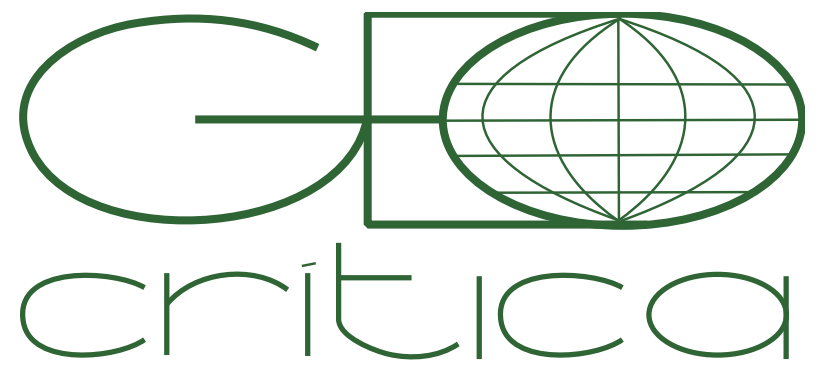

\section{Scripta Nova}

Revista Electrónica de Geografía y Ciencias Sociales Universitat de Barcelona

ISSN: $1138-9788$

Vol. 25, Núm. 2 (2021), p.155-178

\title{
"YA NO TENEMOS FUERZAS". LA GENTRIFICACIÓN DE LOS MOVIMIENTOS ANTIGENTRIFICACIÓN: UNA REFLEXIÓN ETNOGRÁFICA
}

\author{
Eva Mompó \\ Universitat de València \\ eva.mompo@uv.es
}

Recibido: 14 septiembre 2020; Devuelto para correcciones: 29 enero 2021; Aceptado: 23 marzo 2021

\begin{abstract}
"Ya no tenemos fuerzas". La gentrificación de los movimientos antigentrificación: una reflexión etnográfica (Resumen)

El artículo analiza los desplazamientos y desposesiones simbólico-materiales de movimientos urbanos posicionados frente a la ciudad neoliberal. A partir de un estudio etnográfico en el barrio del Cabanyal (Valencia), se abordan las políticas urbanas y las movilizaciones vecinales en una gentrificación inacabada. El análisis muestra, en primer lugar, cómo el desplazamiento de la vecindad-activista y la desposesión de sus espacios colectivos no acarrea su desaparición, sino su transformación. En segundo lugar, la gentrificación y quienes la resisten, emergen como un mismo fenómeno contradictorio marcado por una expansión del urbanismo neoliberal a través de espacios no mercantilizados y culturalmente diferenciados, como los que generan los movimientos. A modo de conclusión se aplica el concepto de gentrificación a los propios movimientos antigentrificación para explicar la pacificación del espacio urbano y la sustitución de actores que cuestionan de manera subversiva el modelo de ciudad neoliberal.
\end{abstract}

Palabras clave: Cabanyal; ciudad neoliberal; gentrificación; movimientos urbanos.

"We no longer have strength". The gentrification of anti-gentrification movements: an ethnographic reflection (Abstract)

The paper analyses the symbolic-material displacements and dispossessions of urban movements facing the neoliberal city. Based on an ethnographic study in the Cabanyal neighbourhood (Valencia), it addresses the urban policies and neighbourhood mobilizations in an unfinished gentrification. The analysis shows, first of all, how the displacement of the neighbourhood-activists and the dispossession of their collective spaces does not lead to their disappearance, but instead their transformation. Secondly, gentrification and those who resist it develop as the same contradictory phenomenon marked by an expansion of neoliberal urbanism through noncommercialised and culturally differentiated spaces, such as those generated by movements. The conclusions apply the concept of gentrification to the very same anti-gentrification movements to explain the pacification of urban space and the substitution of actors who subversively question the neoliberal city model.

Key words: Cabanyal; neoliberal city; gentrification; urban movements. 
Antes de cerrar sus puertas en septiembre de 2019, el Centro Social Okupado Autogestionado La Fusteria, en el barrio del Cabanyal de la ciudad de Valencia, emitía un comunicado de despedida donde afirmaba:

"La desaparición del proyecto del CSOA La Fusteria supondrá un punto más en la pérdida de espacios colectivos en el Cabanyal [...]. Con la oleada de gentrificación no hay lugar para la autogestión y para propuestas liberadoras [...]. Aunque el CSOA La Fusteria desaparece como espacio, sabemos que sus propuestas seguirán vivas en otras asambleas y colectivos, pero sin duda es momento también de reflexionar por qué la gentrificación avanza tan rápido y los movimientos de resistencia caminan de forma tan lenta y anquilosada ${ }^{1 " .}$

Este fragmento nos introduce en un proceso particular de gentrificación, localizado en el Cabanyal, donde el desplazamiento alcanza a actores colectivos autoorganizados al margen de instituciones públicas, autogestionados y posicionados frente a la gentrificación. El manifiesto también invita a una reflexión sobre la velocidad de esta dinámica, en comparación con el ritmo de los movimientos urbanos. No extraña esta llamada si pensamos que la gentrificación, como fenómeno global de desposesión en el marco del urbanismo neoliberal, no deja de reinventarse y expandirse a través de procesos particulares de “destrucción creativa” (Schumpeter 2003; Harvey 2006). Dada su vigencia y capacidad de adaptabilidad a nuevos contextos, continúa siendo necesario investigarla porque, con toda su diversidad y aun con algunos excesos, no ha perdido su potencial para denunciar el desarrollo geográfico desigual (Smith 1996; Slater 2015; Wacquant 2015; Lees, Shin y LópezMorales 2016).

Siguiendo esta línea teórica crítica, este trabajo pone el énfasis en el dinamismo de los movimientos urbanos a lo largo de un proceso de gentrificación. En particular, se abordan aquellos que reclaman el derecho a la ciudad desplegando alternativas a la dinámica urbana capitalista y, en general, a la globalización neoliberal, desde el arraigo en sus barrios y ciudades. Estos movimientos frente a la ciudad neoliberal se inscriben en una larga lucha de defensa del territorio en la cual la gentrificación representa aquello que se pretende transformar, hasta el punto que Benach y Albet (2018) plantean que la antigentrificación se ha convertido en un fenómeno global. No son dos procesos aislados, sino uno solo. El análisis se centra en la relación entre estos actores y las dinámicas de desplazamiento teniendo en cuenta que no sólo las resisten, sino que forman parte de ellas. En ese sentido, se trata de explorar la gentrificación en los propios movimientos urbanos como un fenómeno de desposesión material y simbólica de la acción colectiva. A partir de un estudio etnográfico en el barrio del Cabanyal, el objetivo es reflexionar sobre las maneras en que la gentrificación transforma los participantes, espacios, narrativas y prácticas de los movimientos frente a la ciudad neoliberal. Se pretende con ello contribuir al debate de los efectos del urbanismo neoliberal porque sabemos sobre discursos y acciones antigentrificación, pero desconocemos en buena medida qué le ocurre a esta "vecindad-activista" mientras ejerce resistencias.

1 Este documento, otros incluidos más adelante y la mayoría de los fragmentos de entrevistas han sido traducidos del valenciano en un siempre controvertido ejercicio de traducción. 
Algunas preguntas guían esta investigación: ¿Cómo el avance del modelo urbano neoliberal desposee a los movimientos? ¿Podemos leer sus transformaciones en clave feminista interseccional? ¿Estaríamos ante fenómenos de desplazamiento de la acción colectiva antigentrificación? En ese caso, ¿de qué maneras y a qué lugares se les desplaza? ¿Las consecuencias implican la desaparición, despolitización o "gentrificación de los movimientos"? Para responder a las cuestiones planteadas, tras esta introducción, en primer lugar, la reflexión teórica gira alrededor de la ciudad neoliberal y los movimientos que la cuestionan. En segundo lugar, el análisis explora las políticas urbanas y las movilizaciones vecinales en el Cabanyal y, en tercer lugar, los tipos de desplazamientos que desposeen a los movimientos de sus participantes y de sus espacios colectivos. A modo de cierre, proponemos aplicar el concepto de gentrificación a los movimientos antigentrificación para abarcar el conjunto de sus desplazamientos y desposesiones simbólico-materiales.

El estudio se basa en una investigación antropológica sobre estos movimientos urbanos en el barrio del Cabanyal. El trabajo de campo se desarrolló entre 2015 y 2019 combinando técnicas cualitativas: la observación participante registrada en el diario de campo que, dada la implicación y la residencia en el Cabanyal se convirtió en "participación observante"; las entrevistas abiertas con orientación biográfica; la fotografía etnográfica; y el análisis de contenido de prensa y de producciones de los movimientos. Todo ello desde una antropología "con los pies en el suelo" basada en la reflexividad, el compromiso y la mirada crítica (Scheper-Hughes 1997). De ahí que este texto comience con un escrito de los espacios autogestionados donde señalan que cierran sus puertas por la gentrificación del Cabanyal y, sin embargo, "las propuestas seguirán vivas". En última instancia, este trabajo trata de comprender las maneras en que estos movimientos se transforman y/o se desplazan sin llegar a desaparecer.

\section{Lo urbano como espacio para la acción: movimientos frente a la ciudad neoliberal}

Dado que la ciudad neoliberal es el marco de este análisis le dedicamos la primera reflexión. A continuación, nos adentramos en la gentrificación $\mathrm{y}$, finalmente, exploramos los movimientos frente a la ciudad neoliberal. El punto de partida es la mercantilización de la metrópolis como un fenómeno que atraviesa cada ámbito de la vida social. Abarca desde la materialidad a la emocionalidad de sus habitantes y transforma bienes, servicios, redes, sentimientos de pertenencia, memorias y todo aquello que conforma los valores de uso. La teoría urbana marxista remarca que el conflicto de clases va más allá del binomio capitaltrabajo para inscribirse en la cotidianidad de lo urbano con la primacía de los valores de cambio (Logan y Molotch 1987; Harvey 2006; Franquesa 2007). El resultado es una imbricación de lógicas entre la ciudad para ser vivida y para ser consumida que, a su vez, se inscriben en una jerarquía global en la que las urbes se han reconfigurado en una búsqueda competitiva por la excelencia para entrar en los mercados globales (Sassen 1991; Swyngedouw, Moulaert y Rodriguez 2002; García 2004; Cucó 2013).

En esta línea, la "destrucción creativa" de la ciudad enfatiza la lógica del urbanismo neoliberal que busca de forma permanente beneficios a base de procesos de devaluación y 
revalorización de un lugar (Smith 1979; Schumpeter 2003; Harvey 2006). Esta "nueva política urbana" se inspira en una política económica neoliberal de precarización del mercado laboral y se traduce en grandes proyectos arquitectónicos, privatización de fondos públicos y en las ciudades marca (Swyngedouw, Moulaert y Rodriguez 2002; García 2004; Cucó 2013). Con este telón de fondo, lo cultural y lo patrimonial devienen elementos fundamentales del "capitalismo cognitivo-cultural" (Scott 2014) o del marketing urbano para crear "ciudades creativas" (Iglesias et al. 2011). Asistimos a una nueva lógica neoliberal de reconversión de territorios marcada por la economía de los intangibles donde el turismo y el patrimonio son la pieza fundamental (Santamarina y Del Mármol 2017). Todo ello está enmarcado en una dinámica donde los distintos actores pugnan por los símbolos y los relatos para imponer su propia definición de la realidad. En ese sentido, Franquesa (2007) enfatiza dos características del urbanismo neoliberal. Por un lado, el uso intensivo de elementos culturales para generar "narrativas legitimadoras" de las remodelaciones urbanas. Por otro, las "medidas paraurbanísticas de corte disciplinario" que privilegian unas prácticas y actores acordes con la generación de capital y castigan las que la obstaculizan en el marco de la "ciudad revanchista" (Smith 1996). De acuerdo con Franquesa (2007), ambos rasgos del urbanismo neoliberal son fundamentales para promover procesos de gentrificación. Los exploramos para aterrizar la reflexión sobre urbanismo neoliberal en una de sus estrategias para implantarse de forma global.

Se ha dado una proliferación de estudios sobre gentrificación desde que Glass (1964) acuñara el concepto para referirse al proceso de sustitución de unas clases sociales por otras con mayor poder adquisitivo. Aquí tan sólo retendremos cuatro aspectos. Primero, la concepción de gentrificación no sólo remite a la sustitución de la vecindad, sino que abarca las transformaciones de las memorias, patrimonios, modos de habitar, sociabilidades, políticas o movimientos (Santamarina y Mompó 2020). Al respecto, Marcuse (1985) se refería a la "presión de desplazamiento" o Franquesa (2007) al "vaciado/llenado", para enfatizar los cambios de narrativas y prácticas de vecindad que conforman el lugar. Janoschka, Sequera y Salinas (2014) remiten a la "gentrificación simbólica" y Benach (2016) a la "desposesión simbólica" para remarcar la pérdida de significados y memorias urbanas. Segundo, la teoría del rent gap (Smith 1979) representa una contribución relevante al poner el foco en el diferencial de renta o en el beneficio de unas dinámicas de inversión/desinversión en el espacio urbano. Su importancia reside también en que ha sido un referente en las movilizaciones vecinales antigentrificación (Lees, Shin y López-Morales 2016). Al respecto, cabe reconocer que los movimientos son productores de saberes y generan conocimientos sobre la gentrificación (Escobar 2010; Santos 2010). Tercero, ésta se produce por etapas ambivalentes y no lineales de abandono, estigmatización, regeneración y mercantilización donde se combina la precarización con la elitización (Sorando y Ardura 2016; Smith 1979). Se trata de una dinámica conflictiva basada en relaciones de poder de clase, como apuntó la teoría marxista, y en desigualdades cruzadas de género, etnicidad, sexualidad, nacionalidad, edad, etc., como han añadido desde la teoría feminista de la interseccionalidad aplicada al espacio urbano (Del Valle 2000; Valentine 2007; Rodó-deZárate 2014; Mompó 2019). Cuarto y último, la gentrificación ha devenido una potente 
metonimia de la ciudad capitalista para algunos movimientos urbanos de todo el mundo. Nos detenemos a analizar estos actores dentro de la diversidad de la acción colectiva.

En el siglo XXI, los movimientos sociales politizan de forma creciente la ciudad, sabedores del protagonismo de lo urbano en la "geografía del capital", como defendieron estudios clásicos reapropiados por movimientos urbanos (Jacobs 2011[1961]; Lefebvre 1968; Harvey 1978; Smith 1979; Castells 1986). Coincidimos con esta aproximación marxista en que el espacio urbano es producido en relaciones capitalistas, pero huimos de visiones antagonistas entre dominación y resistencia o entre neoliberalismo y movimientos. Más bien estamos ante un continuum entre lo normativo y lo subversivo donde los actores se mueven entre la reproducción y la transformación de la ciudad neoliberal (Santamarina y Mompó 2018). Siguiendo la clasificación no excluyente de Bonet y Martí (2008), encontramos movimientos urbanos relacionados con el acceso a la vivienda y con la provisión de equipamientos y servicios, como fue detectado por Castells (1986). Otros se organizan a partir de la defensa del barrio o contra ciertos planes urbanísticos neoliberales. También existen asociaciones que gestionan servicios comunitarios o los "movimientos de los excluidos", como los formados por migrantes. Por último, los autores añaden el movimiento alterglobalización cuya hibridación con los movimientos urbanos va en aumento en el siglo XXI dando lugar a lo que aquí denominamos "movimientos frente a la ciudad neoliberal". Esta categoría nos sirve para poner el énfasis en que son actores colectivos territorializados que politizan las ciudades al concebirlas como el lugar donde se materializa la globalización neoliberal (Zibechi 2011; Mayer 2012; Harvey 2013). Como propone Massey, lejos de una perspectiva esencialista, el "sentido global del lugar" nos permite entender el espacio urbano en relación con otros, elaborado desde lo plural y la negociación (Massey 2012; Albet y Benach 2012). De este modo, el lugar es también donde se pueden trazar alternativas al capitalismo global con "políticas del lugar" articuladas en lo local (Escobar 2010).

Las metrópolis se han convertido en el lugar por excelencia de la acción colectiva más subversiva que busca una "globalización contrahegemónica" (Santos 2010). Sin embargo, no existe un consenso teórico para definir estos movimientos llamados "anticapitalistas" (Juris 2010; Harvey 2013), "radicales" (Graeber 2009), “alternativos" (Martínez 2007), "autónomos" (Day 2005; Böhm, Dinerstein y Spicer 2010; Escobar 2010), entre otras más o menos vinculadas a la antigentrificación. Estos estudios son fuente de inspiración para construir de forma teórica una categoría analítica que sustenta esta etnografía. Este trabajo prioriza la noción de "movimientos urbanos frente a la ciudad neoliberal" por varios motivos. Por un lado, "movimientos" porque son proyectos colectivos conectados en escalas más allá de lo local, duraderos en el tiempo y más o menos coincidentes en diferentes contextos. Y "urbanos" para subrayar su arraigo en la ciudad, sus reivindicaciones encaminadas a la reapropiación de la urbe, así como para entenderlos como actores clave en la construcción social del conflicto en la ciudad (Hamel, Lustiger-Thaler y Mayer 2000; Bonet y Martí 2008). Por otro, "frente a la ciudad neoliberal" pone el énfasis en las propuestas alternativas al modelo de ciudad capitalista y a la globalización neoliberal. La etiqueta "antigentrificación" (o anticapitalista) deviene reduccionista en la medida en que se concentra en una estrategia del urbanismo neoliberal, la gentrificación, y la partícula "anti" sólo denota una postura reactiva, pero omite la vertiente creativa, proactiva y prefigurativa de estos movimientos al 
posicionarse "frente a" las hegemonías. La política prefigurativa remite a poner en práctica las reivindicaciones a través de las propias dinámicas. Es decir, si las aspiraciones giran en torno a alcanzar una democracia radical, una globalización desde abajo y unas ciudades inclusivas bajo lógicas distintas al neoliberalismo, las formas de articulación y las iniciativas buscan constituirse como experiencias de esos objetivos. Esto se traduce en unas maneras de acción y organización basadas en la autogestión, la autoorganización, la búsqueda de autonomía respecto a las instituciones públicas, la acción directa o el asamblearismo (Day 2005; Graeber 2009; Böhm, Dinerstein y Spicer 2010). Se trata de grandes rasgos compartidos por movimientos urbanos frente a la ciudad neoliberal de todo el mundo y adaptados a las singularidades de cada lugar.

Las resistencias se ejercen en un encuentro permanente entre lo local y lo global marcado por las formas particulares de experimentar la violencia del capitalismo (CepedaMásmela 2019). Algunos estudios se refieren a las nuevas geografías del malestar que, en el caso de Europa, responden a la creciente precarización, al aumento de las desigualdades urbanas y a la explosión de revueltas sociales más o menos efímeras (Romero 2019). En este marco emerge la "indignación" como uno de los motores de la acción colectiva del siglo XXI movilizando a actores precarizados que comienzan a sufrir unos problemas estructurales a los que hasta entonces se enfrentaban las clases obreras (Feixa y Nofre 2013). Se conforman unos "paisajes de rebeldía" a partir de tramas activistas que, ancladas en lo local, se engarzan en redes globales (Diz 2018). Estos espacios de descontento y resistencia están presentes desde el inicio de los procesos de gentrificación, aunque de forma paradójica, pueden llegar a fomentarlos (Mayer 2016; Sorando y Ardura 2016). Algunas expresiones culturales de estos movimientos pueden capitalizarse $\mathrm{y}$, por ejemplo, se han vinculado con representaciones de la ciudad creativa en Berlín, Hamburgo o Amsterdam (Shaw 2007; Novy y Colomb 2013). Como señala esta literatura centrada en Europa, los movimientos frente a la ciudad neoliberal pueden ser cooptados e institucionalizados en su vertiente artísticacultural y, al mismo tiempo, criminalizados, ignorados o reprimidos en cuanto a sus demandas de ejercer el derecho a la ciudad o sus luchas por la vivienda. Al respecto Janoschka, Sequera y Salinas (2014) evidencian que, en España y en América Latina, los procesos de gentrificación van de la mano de la higienización del espacio mediante el desplazamiento de prácticas no deseadas. En definitiva, estamos ante una intensa disputa territorial en la que los movimientos urbanos buscan articularse como contrapoderes desde abajo (Zibechi 2008). En esta línea, en las siguientes páginas pretendemos indagar cómo algunos de ellos politizan el Cabanyal en sus luchas frente a la gentrificación y cómo se inscriben en la memoria de su ciudad en una dinámica marcada por la presión de desplazamiento.

\section{Las fisonomías del Cabanyal a través de las fases de su gentrificación}

Hoy es difícil aproximarnos al Cabanyal sin que medien imágenes preconcebidas sobre este barrio. El Cabanyal se ha convertido en un "fenómeno global", en la medida en que ha sido un referente local, nacional e internacional de conflicto urbano y resistencia vecinal (Santamarina y Mompó 2020). En las líneas que siguen, más que describirlo, analizaremos 
algunas de sus políticas urbanas y las movilizaciones desplegadas frente a ellas en las dos últimas décadas ${ }^{2}$. Antes, nos situamos en el Cabanyal, un barrio del distrito de Poblados Marítimos en el litoral de Valencia. Este rasgo lo ha trasladado, de forma simbólica y política, del margen de la ciudad al centro de las políticas urbanas neoliberales.

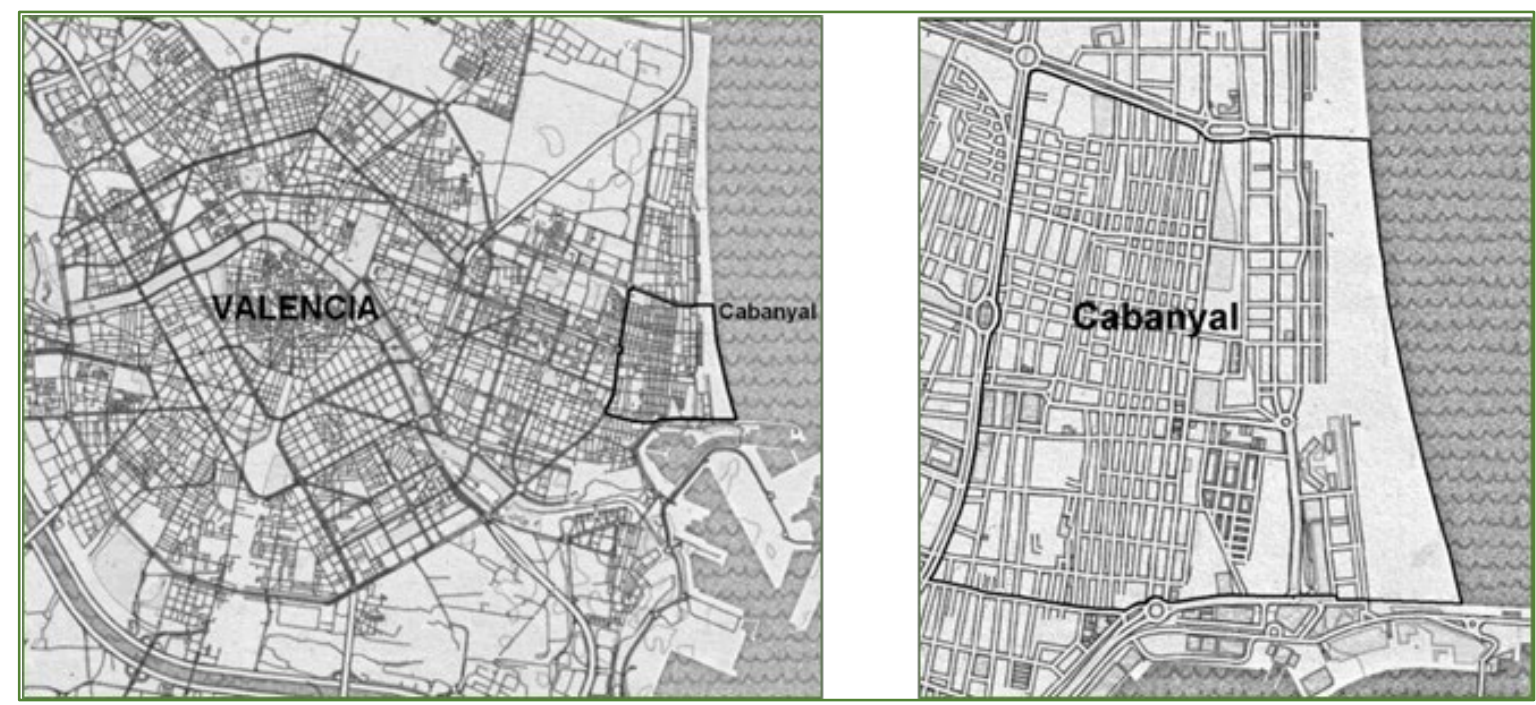

Mapas 1 y 2. Localización del Cabanyal

Fuente: Elaboración propia.

El Plan General de Ordenación Urbana de Valencia de 1988 puede ser un punto de inicio porque sentó las bases para un modelo urbano empresarial (Gaja 2000) y estableció el marco de actuaciones que vendrían de la mano del gobierno conservador municipal (19912015) y autonómico (1995-2015). Reconoció el Cabanyal como conjunto histórico y, en 1993 una parte fue declarada Bien de Interés Cultural. En 1998 se impulsó el Plan Especial de Protección y Reforma Interior del Cabanyal-Canyamelar (PEPRI) que planificó la prolongación de la avenida Blasco Ibáñez hasta el mar. Una arteria que dividía el barrio por la mitad y suponía la demolición de 1.651 viviendas. El PEPRI se enmarca en procesos más amplios en los que Valencia incorporó las nuevas políticas urbanas (Swyngedouw, Moulaert y Rodriguez 2002) y seleccionó el water front como zona prioritaria para la especulación inmobiliaria (Cucó 2013; 2014; Boix, Rausell y Abeledo 2017). Este "modelo Calatrava” (Boix, Rausell y Abeledo 2017) implicó macro eventos y "mega complejos con sello de autor" que, de forma significativa, se llevaron a cabo en el litoral de Valencia ${ }^{3}$ (Santamarina 2014). El resultado ha sido una polarización socioespacial con zonas orientadas al turismo y otras marcadas por la precarización. Esta dualidad adquiere su sentido en la gentrificación del Cabanyal con cuatro etapas que se superponen. Las exploramos a continuación con énfasis en las más recientes.

2 Su nombre oficial es Cabanyal-Canyamelar. Existe una amplia bibliografía que lo describen, entre otros, Boira (1987), Sanchis $(1997 ; 1998)$ o Santamarina (2009). Para una revisión de la literatura sobre el Cabanyal véase Mompó (2019) y Santamarina y Mompó (2020).

3 Sirva como ejemplo la Ciudad de las Artes y las Ciencias y la Marina Real Juan Carlos I o la Copa América y el Gran Premio de Europa en el circuito urbano de Fórmula 1. 
En la primera, o fase previa de abandono, una parte de la vecindad dejaría de residir en este barrio obrero marcado por la desinversión. Antes, entre los años cuarenta y setenta, se había producido una industrialización y proletarización en la zona marítima (Boira 1987; Cucó 2014). En la década de los setenta y ochenta vendría el despoblamiento con la pérdida de casi un tercio de la población, de 32.000 habitantes en 1970 a 22.000 en 1991. Abrimos un paréntesis para señalar que la tendencia continúa, de forma menos acusada y, en la actualidad, residen 19.497 personas ${ }^{4}$. En esta etapa de abandono, las Asociaciones de Vecinos y Vecinas (AA.VV.) nacidas a finales de 1970 son muy activas con demandas de servicios comunitarios, de forma similar a otros barrios obreros (Castells 1986).

La segunda fase, en los años noventa, está marcada por el inicio de la estigmatización y la degradación que da lugar a un parque inmobiliario accesible al que llegarían poblaciones precarizadas. Al mismo tiempo, se profundiza en la representación del barrio como gueto y marginal. Una narrativa alimentada por los poderes públicos que se utilizaría para justificar los planes de renovación ${ }^{5}$. La destrucción creativa en su vertiente destructiva conseguía el máximo valor del rent gap gracias al vaciado poblacional y simbólico.

En la tercera etapa de regeneración se inicia la inversión para asegurar un beneficio derivado del diferencial de renta. En este marco se sitúa el PEPRI con el plan de prolongación de la avenida propuesto por el gobierno municipal con mayoría absoluta del Partido Popular. Se desarrolló a través de una degradación especulativa llevada a cabo por la corporación público-privada Cabanyal 2010 S.A., en especial en la denominada "zona cero" donde estaba planeada la prolongación ${ }^{6}$.

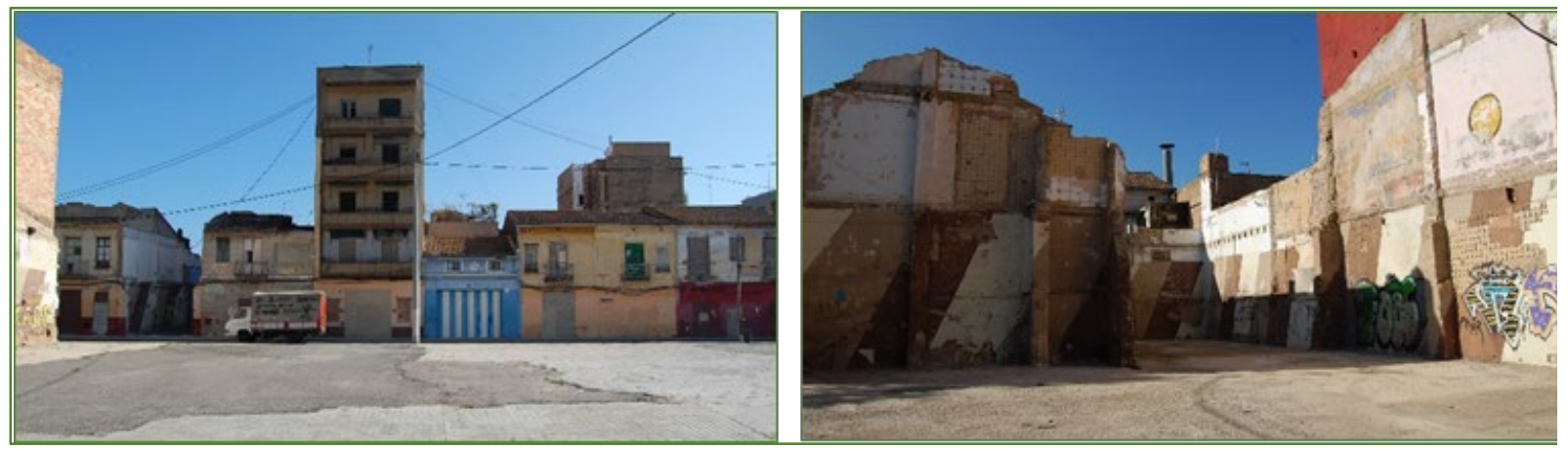

Imagen 1 y 2. Solares y viviendas tapiadas en la zona cero (2015).

Fuente: Elaboración propia.

Esta degradación inducida generó un parque inmobiliario que fue habitado por población precarizada. Entre la nueva vecindad llegaron jóvenes, algunos de los cuales

4 Todos los datos provienen de la Oficina de Estadística del Ayuntamiento de Valencia si no se indica lo contrario.

5 Julio Martínez, presidente del Partido Popular del Marítimo afirmaba en 1996: "la prolongación de Blasco Ibáñez es progreso porque impulsará la situación económica de la zona, sino nos vamos a convertir en un ghetto" (01/05/1996). http://cabanyal.com/1996/05/01/espanol-el-presidente-popular-del-maritimoconsidera-al-pp-infinitamente-mas-progresista-que-el-psoe/

6 Sobre la degradación véase Santamarina (2009; 2014), Ruiz y García Pilán (2013) o Santamarina y Mompó (2020). 
pasarían a formar parte de los movimientos frente a la ciudad neoliberal. Habitaron viviendas de la zona cero con alquileres asequibles u okuparon edificios vacíos y/o amenazados de derribo. Esta inserción residencial plural fue similar a la de personas procedentes de Rumanía (una parte significativa romá) que aumentaron la diversidad étnico-cultural en el Cabanyal (Torres et al. 2016) ${ }^{7}$. El PEPRI fue acompañado de discursos culturalistas que subrayaban el "exceso" de diferencia cultural entre población paya, gitana o romá y de representaciones en torno al barrio como "un problema público" por su "guetización" y marginación. Al mismo tiempo, aumentó la estigmatización de la okupación, a menudo bajo los calificativos de "radicales" o "antisistemas" 8 .

Las políticas urbanas no sólo conllevaron cambios en las narrativas y la composición poblacional, sino también en el tejido de movimientos urbanos. El PEPRI de 1998 fue también un momento de inflexión en la historia del Cabanyal por la gran movilización de oposición. A las existentes AA.VV., se añadirían formas de acción colectiva desconocidas en el Cabanyal hasta ese momento. En 1998, nace Salvem el Cabanyal y el primer Centro Social Okupado La Pilona. Este CSO representa el inicio de los movimientos frente a la ciudad neoliberal que irían multiplicándose: Ateneu Llibertari y Radio Malva (1999) o los CSO Malas Pulgas (2000) y Samaruc (2001). Los conflictos abren oportunidades a otras maneras de relacionarse en y con el espacio urbano (Mompó 2016) y, a la lista anterior se añadirían los CSO Proyecto Mayhem (2006) y La Fusteria (2009), el Centre Cultural L'Escola (2010) y Cabanyal Z (2012), entre otros. Una mención aparte merece Units pel Cabanyal (2012), una plataforma que, durante un tiempo, reunió a actores del movimiento vecinal: Salvem, la Asociación de Comerciantes y las AA.VV. Todo este tejido, excepto Sí Volem que fue la organización de defensa del PEPRI, desplegaron una pluralidad de movilizaciones y paralizaron el plan gracias a una orden del Ministerio de Cultura ${ }^{9}$. Salvem fue el colectivo clave por su estrategia judicial y de defensa del patrimonio (Santamarina 2014). Sin embargo, los movimientos frente a la ciudad neoliberal habían desarrollado diversos proyectos autoorganizados al margen de las instituciones públicas que serían muy activos en la fase final de la gentrificación.

La cuarta y última etapa inacabada viene marcada por la mercantilización. Podríamos situarla desde 2015 con la llegada de un gobierno municipal "del cambio" 10 hasta la actualidad con la tramitación del Plan Especial del Cabanyal. El nuevo consistorio derogó el PEPRI y auguró políticas participativas enfocadas a la rehabilitación que se desarrollaron en un ritmo urgente para solicitar fondos europeos y no incluyeron a toda la vecindad ni su diversidad (Santamarina y Mompó 2018). Entre 1998 y 2015, las estrategias de degradación ya se habían combinado con la elitización y turistificación, por ejemplo, con la creación de

7 Algunos titulares en relación con las viviendas precarias: "Las familias rumanas desalojadas del bulevar San Pedro ocupan solares y casas", Levante-EMV, 19/07/2007 o "Una empresa municipal alquila infraviviendas en El Cabanyal", El País, 15/03/2008.

8 Ejemplo de ello son las noticias "Radicales en contra del plan del Cabanyal tabican la sede municipal" (Las Provincias, 16/05/2006) o "El Cabanyal entra en la agenda de los antisistema” (Las Provincias, 11/04/2010).

9 https://www.boe.es/diario_boe/txt.php?id=BOE-A-2010-370

10 El ayuntamiento de la ciudad está liderado por Joan Ribó, alcalde de Compromís en tripartito con el Partit Socialista del País Valencià y València en Comú (a partir de 2019 sin este último). 
macro edificaciones en el litoral. Sin embargo, llegarían con fuerza a partir de 2015 de la mano de una revalorización. En esta fase creativa de la destrucción aparecieron grupos de inversiones y residentes de mayor poder adquisitivo que intensificaron la sustitución poblacional. Sirvan algunas cifras de ejemplo. Respecto a la vecindad extranjera, la principal nacionalidad sigue siendo la rumana, pero desciende de modo significativo pasando de representar el 41\% de la población extranjera a ser el 26\% entre 2015 y 2019. En el mismo periodo, se amplía el número de habitantes originarios de Italia, Francia y Reino Unido, del $10 \%$ de población extranjera a ser el 18\%. En relación con las actividades económicas en el Cabanyal para el mismo periodo, se registra una tendencia a la terciarización con el aumento del $10 \%$ en comercio y servicios o del $43 \%$ en las actividades profesionales, sobre todo ligadas a los sectores de hostelería, finanzas, inmobiliario o jurídico, entre otras.

En esta fase, la "presión de desplazamiento" (Marcuse 1985) comenzó a resentirse con fuerza entre capas subalternas de la población afectando especialmente a personas atravesadas por desigualdades de género, etnia y/o edad (lo retomaremos más adelante). En 2015 los movimientos frente a la ciudad neoliberal denunciaron las subidas excesivas en los costes de alquiler o la no renovación de contratos, los desalojos en viviendas okupadas y el control punitivo del espacio urbano con medidas de higienización, en su mayoría a personas de etnia gitana o romá (por ejemplo, sanciones económicas por el chatarreo o por tender ropa en la calle). En esta fase las "medidas paraurbanísticas de corte disciplinario" (Franquesa 2007) no dejaron de aplicarse, como recogía un titular: "Más policía para conseguir la 'rehabilitación social' del Cabanyal" (elDiario.es, 30/10/2015).

Frente a este panorama, con ecos de la ciudad revanchista, emerge una red de solidaridad vecinal para hacer frente a distintas presiones de desplazamiento y reclamar el derecho a la ciudad. Este es el origen de movimientos como Espai Veïnal del Cabanyal per un procés de participació autoorganitzat, Cabanyal Horta con la reapropiación de un "solar vertedero" para convertirlo en jardín urbano autogestionado o La Col-lectiva en un edificio en la zona cero con proyectos artísticos, de intervención socioeducativa o de defensa de la interculturalidad barrial. Estos colectivos surgieron en 2015 posicionados contra la gentrificación y con el objetivo de crear espacios de encuentro de la vecindad. A lo largo del conflicto, los proyectos frente a la ciudad neoliberal aprovecharon las oportunidades socioespaciales abiertas por las políticas de degradación para disponer de un lugar de reunión (okupado, cedido o alquilado a bajo coste). No es una casualidad que sus ubicaciones se superpongan con relativa precisión a la zona cero donde se había proyectado la prolongación de la avenida (en sombreado en el mapa 3) ${ }^{11}$.

En esta última fase también se agudizaron los procesos de turistificación o gentrificación turística, alentados por el Plan Especial del Cabanyal (PEC). Este nuevo proyecto para el Cabanyal, desde 2019 en fase de tramitación, ha reabierto con fuerza el conflicto urbano. La versión preliminar alerta en diversas ocasiones sobre "la eventual gentrificación" y, al mismo tiempo, la presentan como inevitable: "al socaire de la revalorización que toda actuación de Regeneración y Rehabilitación Urbana

11 La ubicación representa su lugar de reunión frecuente, aunque sus campos de actuación desbordan estos límites. 
insoslayablemente comporta ${ }^{12 " . ~ E l ~ t e x t o ~ s e n ̃ a l a ~ l o s ~ p e l i g r o s ~ d e ~ l a ~ g e n t r i f i c a c i o ́ n ~ y ~ l a ~}$ turistificación mientras establece actuaciones que pueden potenciarlas, entre otras, un controvertido hotel de quince alturas, la "limitación" al 40\% de viviendas de uso turístico en algunas zonas, la edificación en los huertos de Cabanyal Horta y la demolición de un bloque de 168 viviendas de la época de la proletarización (1954), habitadas por población precarizada en su mayoría de etnia gitana. Los ecos con el antiguo PEPRI del gobierno conservador y la orientación neoliberal del PEC no dejaron indiferentes a los movimientos urbanos que se autoorganizaron en un proceso participativo que culminó en 2019 con la presentación de más de mil alegaciones y un nuevo colectivo: Cuidem Cabanyal ${ }^{13}$.

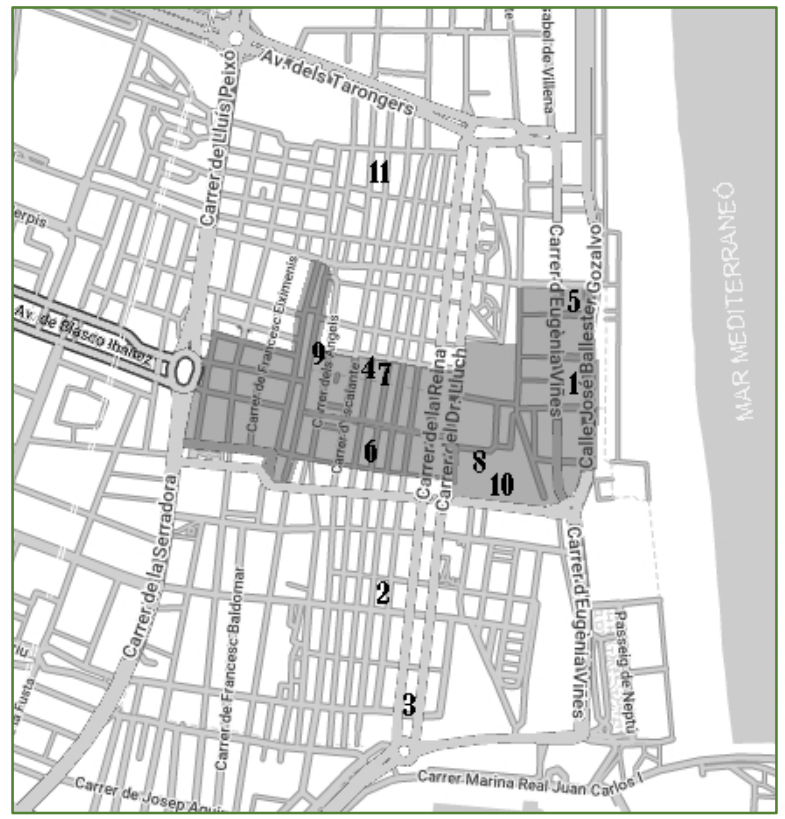

\begin{tabular}{ll}
\hline 1 & CSO La Pilona \\
2 & Radio Malva, Ateneu Llibertari \\
3 & CSO Malas Pulgas \\
4 & CSO Samaruc, Cabanyal Z \\
5 & CSO Proyecto Mayhem \\
6 & Centre Cultural L'Escola \\
7 & CSOA La Fusteria \\
8 & Espai Veïnal \\
9 & La Col-lectiva \\
10 & Cabanyal Horta \\
11 & Cuidem Cabanyal \\
\hline
\end{tabular}

Mapa 3. Zona cero y movimientos frente a la ciudad neoliberal.

Fuente: Elaboración pròpia

El conflicto se ha agudizado con la reapertura de un segundo proceso de alegaciones públicas durante el Estado de alarma (04/06/2020), con los derechos de reunión y participación limitados ${ }^{14}$. A pesar de estas dificultades, han presentado nuevas alegaciones donde solicitan, entre otros, la limitación al 5\% de la vivienda turística, la no edificación del hotel o el respeto de Cabanyal Horta. También cuestionan la distinción entre zonas del litoral orientadas al turismo y otras a la población actual. Una dualidad entre la elitización y la precarización que, alimentada por los sucesivos planes urbanísticos neoliberales, sigue siendo fuente de disputas. Aunque las fisonomías del Cabanyal van cambiando, responden a una misma gentrificación que, por fases, sirve de espejo para reflejar resistencias vecinales.

12http://www.valencia.es/ayuntamiento/urbanismo2.nsf/0/A7FB1D670AB26BD2C125840F004165A8/\$FI LE/223-2016\%20Memoria\%20Justificativa.\%20PEP\%20Cabanyal-Canyamelar firmado.pdf?OpenElement

13 Pueden consultarse en: https://cabanyal-canyamelar.com/

14 http://www.dogv.gva.es/datos/2020/06/04/pdf/2020_3892.pdf 


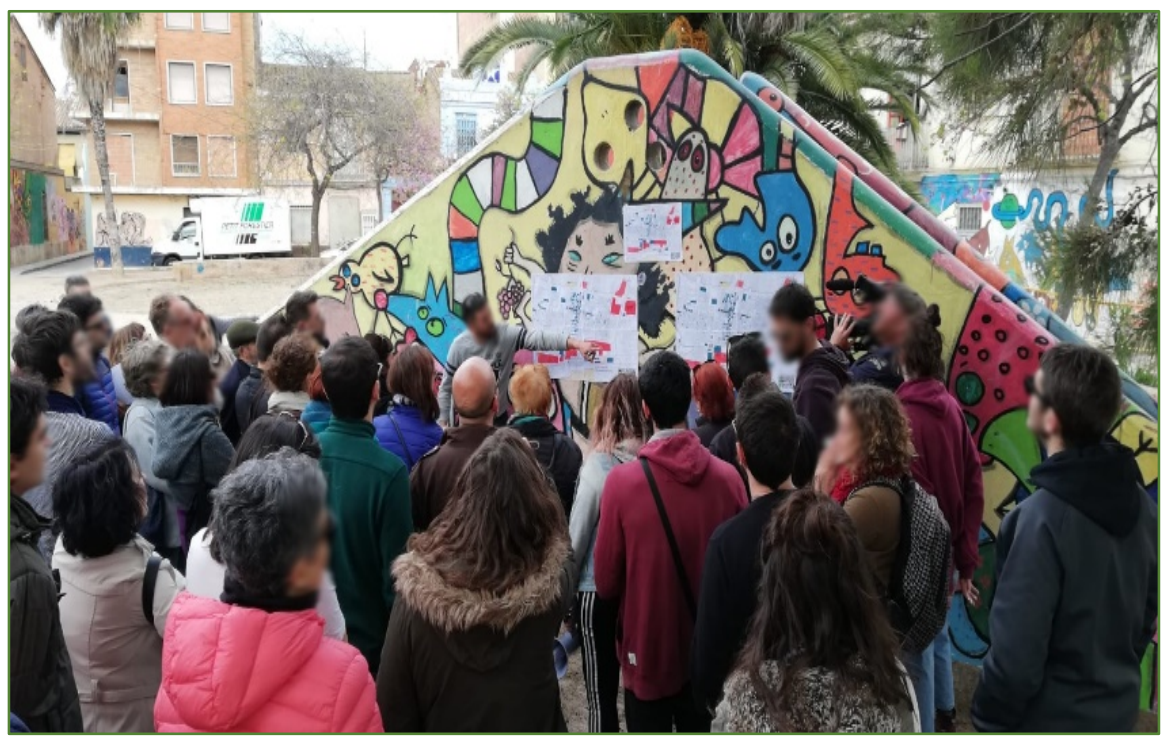

Imagen 3. Preparando las alegaciones al PEC (2019).

Fuente: Elaboración propia.

\section{"Ya no tenemos fuerzas". Desposesión y desplazamiento de activistas y espacios colectivos}

En los últimos años la gentrificación del Cabanyal afecta de forma significativa a los movimientos frente a la ciudad neoliberal. A través del análisis etnográfico, basado en el trabajo de campo entre 2015 y 2019, exploraremos la desposesión y el desplazamiento de estos actores colectivos en dos sentidos interrelacionados: el vaciado de sus participantes y la pérdida de sus espacios colectivos.

Respecto a los efectos de la gentrificación en los miembros de los movimientos, podríamos referirnos a algunas trayectorias para "venir a vivir al Cabanyal" y para "marcharse del barrio". Gracias a las entrevistas de orientación biográfica, emergían numerosos itinerarios de llegada al barrio que tenían un denominar común: la mudanza al Cabanyal era percibida como un acto en sí mismo de resistencia, a la prolongación en un primer momento y a la gentrificación más tarde. En sus relatos en primera persona suele aparecer el nombre de un proyecto donde entran a formar parte al poco de su traslado o incluso antes de venir al barrio, hecho que motiva su cambio de residencia, como en el caso de Pau que recordaba en una entrevista su llegada doce años atrás: "vinimos directamente al Cabanyal en el mes de septiembre porque ya conocíamos a la gente [...] estuve en la asamblea preparatoria para okupar y okupamos el [CSO] Mayhem y ese es el primer contacto con el Cabanyal" (27/03/2018).

Sin embargo, tal vez otro itinerario de interés para el caso que nos ocupa sea el de quienes llegaron desplazadas de otros conflictos urbanos, en buena medida de La Punta, donde la lucha vecinal se enfrentó a la Zona de Actividad Logística del puerto de Valencia. Este proyecto fue finalmente llevado a cabo y supuso la destrucción de casas y huertas, así como el desplazamiento de una parte de la vecindad (Cucó 2009). Al respecto, Mar, participante en diferentes colectivos del Cabanyal, contaba: "Después de la experiencia de La 
Punta [...] pensábamos que estratégicamente teníamos que venir a okupar aquí para resistir que hicieran la avenida de Blasco Ibáñez, por eso vinimos aquí. También era utilizar la okupación como una herramienta de resistencia, como defensa del territorio, igual que se había hecho en La Punta" (31/05/2017). La trayectoria de Mar es compartida por otras vecinas. En su caso, tras trece años de residencia en el Cabanyal en la misma vivienda okupada con el consentimiento del propietario, éste les solicitó su abandono en 2017 en el marco de la revalorización del Cabanyal. Aceptaron marchar como señalaba Mar: "okupé esta casa con una intención de paralizar la avenida y la gentrificación y creo que ya ha pasado la etapa, ya está, no hemos conseguido lo que queríamos".

El desplazamiento de vecinas activistas es algo gradual en los últimos años y forma parte de las conversaciones cotidianas en las que compartimos los destinos de los traslados. De manera generalizada, se trata de situaciones en las que el coste del alquiler de las viviendas sube de forma inasumible, no se renueva el contrato para ponerlas a la venta o transformarlas en apartamentos turísticos y se desalojan viviendas okupadas. A menudo, algunos fondos de inversiones se encuentran detrás de estos cambios. En este marco, el Espai Veïnal, una asamblea autoorganizada, reorientó su estrategia en dos direcciones. Por un lado, denuncia el avance de la gentrificación de forma pública junto con otros colectivos, entre los que destaca Radio Malva, situada en el Ateneu Llibertari, que abre el micro a personas bajo presión de desplazamiento para difundir sus testimonios. Por otro, genera una "red de apoyo mutuo" para buscar alternativas a los desplazamientos. Esta red se ha traducido en asesoramiento jurídico, acompañamientos de familias desalojadas a okupar otra vivienda, concentraciones en las puertas de los domicilios para evitar expulsiones, etc. Estas tramas vecinales de apoyo mutuo responden a una política prefigurativa con una aspiración más amplia como afirma Ferran: "uno de los objetivos más importantes del Espai Veïnal es crear una comunidad de resistencia" (27/01/2016). Ésta es definida por algunas activistas como un sujeto político colectivo con necesidades comunes que, de manera autoorganizada, se enfrente a la ciudad capitalista y, en particular a la gentrificación, mediante la defensa del espacio urbano bajo el lema "el barrio para quien lo habita".

Desde lo recogido en el trabajo de campo y, en concreto, en la participación observante en estos movimientos urbanos, podemos afirmar que las trayectorias de desplazamiento de esta vecindad están influidas por sus precariedades laborales, económicas y residenciales. Su autoidentificación de clase les permite generar posiciones anticapitalistas y, por extensión, antigentrificación, al concebirla como un proceso de expulsión de las clases populares y precarias a las que sienten pertenecer. Margarita lo resumía de forma contundente: "Por pobres vinimos al Cabanyal y por pobres nos iremos de él” (15/03/2016). Sin embargo, esta variable de clase social intersecciona con la edad, el género y la etnia. Las personas que marchan o están bajo presión son, de forma significativa, jóvenes y/o mujeres y/o de etnia gitana. Esto se manifiesta en varios ejemplos. Uno de ellos es el proyecto de destrucción del bloque de Clot habitado mayoritariamente por personas de etnia gitana y bajo un fuerte control policial ${ }^{15}$. Uno de sus habitantes años atrás preveía un futuro difícil en una entrevista: "los gitanos estamos concentrados allá, allí nos dejarán de 
momento, harán una valla como en Varsovia" (Manuel, 18/11/2016). En ese sentido, Espai Veïnal denunciaba que "el mayor acoso policial a las familias sin recursos y a los jóvenes del barrio es innegable" (11/2015) o el mismo Manuel en una reunión con la concejala de protección ciudadana (PSOE): "eso se lo expuse yo a Sandra Gómez, le dije estáis poniéndole denuncias a gente, estáis haciendo firmar a gente que no sabe ni leer este idioma, a gente analfabeta que firman con una cruz [...] ¿esa es la policía integradora ${ }^{16 ? ” . ~ E n ~ e s t a ~ l i ́ n e a, ~ v a r i a s ~}$ mujeres han recibido sanciones económicas por enganches a los suministros (electricidad o agua) y han solicitado apoyo mutuo a través del Espai Veïnal para recoger dinero de forma colectiva a través de la autogestión. Desde 2018, buena parte de los casos de expulsiones en viviendas de alquiler por fondos de inversiones son a mujeres, y de forma significativa, a familias monomarentales encabezadas por mujeres. Desde un punto de vista cualitativo, basado en la etnografía, podríamos afirmar que estamos ante una gentrificación feminizada, juvenil y etnificada.

Siguiendo con el desplazamiento de personas vinculadas a los movimientos cabría preguntarse: ¿a dónde se mudan? Detecté dos principales itinerarios de "marcharse del barrio". Algunas buscaban otras viviendas de alquiler en los barrios colindantes para "seguir haciendo vida de barrio en él, aunque ya no pueda pagar un alquiler en el Cabanyal" (Susana, 05/03/2018). Aunque permanecían conectadas a sus colectivos, cada vez la asiduidad era más frágil por la mayor distancia a recorrer para acudir a una asamblea o actividad y la fractura en el sentimiento de pertenencia al Cabanyal. Otras se mudaban a barrios obreros de la periferia, por ejemplo, a Natzaret o a Orriols para, como afirmaba Damián: "encontrar el Cabanyal de hace años donde volver a organizarnos con lo ya aprendido" (15/01/2019). Damián, igual que otras personas, con sus desplazamientos desde La Punta al Cabanyal quince años atrás y desde éste a Orriols, tejía redes entre colectivos frente a la ciudad neoliberal. Estas redes reflejan el "poder acumulativo" (Tarrow 1997) de los movimientos que se mueven de un conflicto a otro a través de participantes que se trasladan con los aprendizajes adquiridos. Esta es una de las maneras de "mantener vivas" las propuestas en otras asambleas y colectivos, como señalaban en el manifiesto de La Fusteria citado al inicio. Sin embargo, no es la única vía, como veremos con la pérdida de lugares de reunión y acción.

El segundo sentido de la desposesión y el desplazamiento de estos movimientos se refiere al vaciado de sus espacios colectivos. La clausura de un proyecto, o la fusión de dos en uno, responden a un fenómeno dinámico de la historia de la acción colectiva en el Cabanyal (Santamarina y Mompó 2018). Sin embargo, la diferencia reside en la intensidad y velocidad con la que desaparecen, o están en riesgo, en los últimos años. Desde 2016 los espacios cierran sus puertas por el vaciado de activistas y por el acuse de la gentrificación traducida en subidas inasumibles de alquiler ( $L^{\prime} E s c o l a$ ), compra de edificios por fondos de inversiones (La Col-lectiva), proyección en el PEC de nuevos edificios (Cabanyal Horta) o desalojos para hacer apartamentos turísticos (CSOA La Fusteria). En este desplazamiento ha influido su ubicación en la zona cero en la que habían aprovechado las oportunidades socioespaciales (ver mapa 3). Se habían reapropiado de lugares degradados desde los que denunciar la

16 En Elperiodic.com: "Sandra Gómez refuerza la Policía de Barrio en El Cabanyal como canal de comunicación con los vecinos" (29/10/2015) 
gentrificación. Sin embargo, esto se volvería en su contra con el avance de la mercantilización que se sirvió de algunos de estos espacios para generar un mayor beneficio en el mercado inmobiliario y, a la vez, conseguir la pacificación del lugar eliminando toda resistencia incómoda. Veamos la crónica de esta desposesión y cómo reaccionan los movimientos a ella.

El Centre Cultural L'Escola nació en 2009 y buscaba enfrentarse, a la degradación primero y a la gentrificación después, con actividades culturales y artísticas "a precios populares". En septiembre de 2016 L'Escola cerró ante una subida de alquiler del local inasumible para el colectivo y la imposibilidad de encontrar otro asequible. Dio paso a un nuevo restaurante y próximamente también hotel. El proceso de fin de un proyecto no está exento de costes emocionales y políticos, en especial para aquellas personas que llevaban años implicadas, tal y como lamenta Alicia: "no lo llevaba bien, de hecho, estuve mucho tiempo sin poder pasar por la puerta de L'Escola, la esquivaba, me iba por otra calle. Le cogí mucho apego, fue mucho tiempo y muy intenso" (21/11/2017).

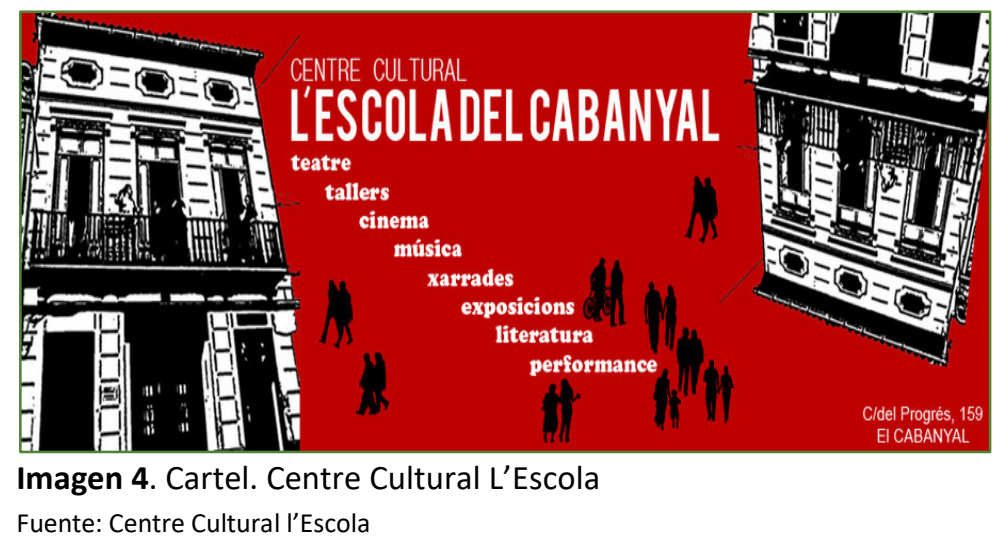

El espacio de $L^{\prime} E s c o l a$ se vacío de un tipo de programación cultural y se llenó de otra en el restaurante. Al respecto, Alicia comentaba con indignación: "empezaron a mandarles carteles de lo que habíamos estado haciendo para decirles: antes de que llegarais vosotros a poner un restaurante estábamos aquí nosotros haciendo cultura gratis para todo el mundo". Los sentimientos de tristeza e indignación son vehiculados mediante acciones cuya finalidad es incorporar los proyectos a la memoria colectiva y, en cierto modo, realizar duelos simbólicos y políticos por sus "muertes". Podríamos afirmar que se trata de "rituales de aflicción" (Cruces 2006) destinados a reparar los daños y a revertir la desposesión simbólica que borra memorias y significados urbanos. Por ejemplo, desde 2016 se realiza un Gentrificatour, una ruta barrial anual que pretende denunciar los efectos de la gentrificación y que cada año se detiene en las puertas de lo que fue L'Escola. Este ritual ha contribuido a convertirla en un símbolo de la gentrificación del Cabanyal para estos movimientos y a anclarla en su memoria colectiva.

L'Escola, poco antes de cerrar, fue el lugar de inicio del primer Gentrificatour (abril 2016) donde se realizó una performance que, a través de la sátira, pretendía canalizar el temor a que el proyecto "muriese" por la gentrificación. Ignacio, micro en mano, explicaba la incertidumbre con ironía: “L'Escola ya lleva ocho o nueve años cuando prácticamente en el 
barrio no había nada, ha sido un lugar para traer cultura al barrio, por lo que tenemos el orgullo y la satisfacción de ¡ser el primer agente gentrificador del barrio! Moriremos de éxito en L'Escola, ¡víctimas de lo que hemos provocado!". El sarcasmo no oculta su conciencia de formar parte de una gentrificación que necesita constantemente incorporar elementos de los márgenes del capitalismo para seguir reproduciéndose. El edificio, en la zona cero, se había conservado gracias al mantenimiento del colectivo con el dinero de la autogestión de las actividades y dejó de ser como los demás para ser único. El urbanismo neoliberal, ávido de mercantilizar la distinción cultural, se aprovecha de estos lugares cargados de memoria y patrimonio para extraerles el máximo beneficio con un marketing urbano basado en la consigna de la autenticidad ${ }^{17}$. En sintonía, el nuevo restaurante destaca en su presentación el patrimonio de su edificio con "la estética típica de este barrio marinero 18 ". Todo ello encierra una contradicción que pesa en estos movimientos conscientes de la atracción que sus acciones y sus espacios pueden generar para la economía de los intangibles y el "capitalismo cognitivo-cultural" (Scott 2014).

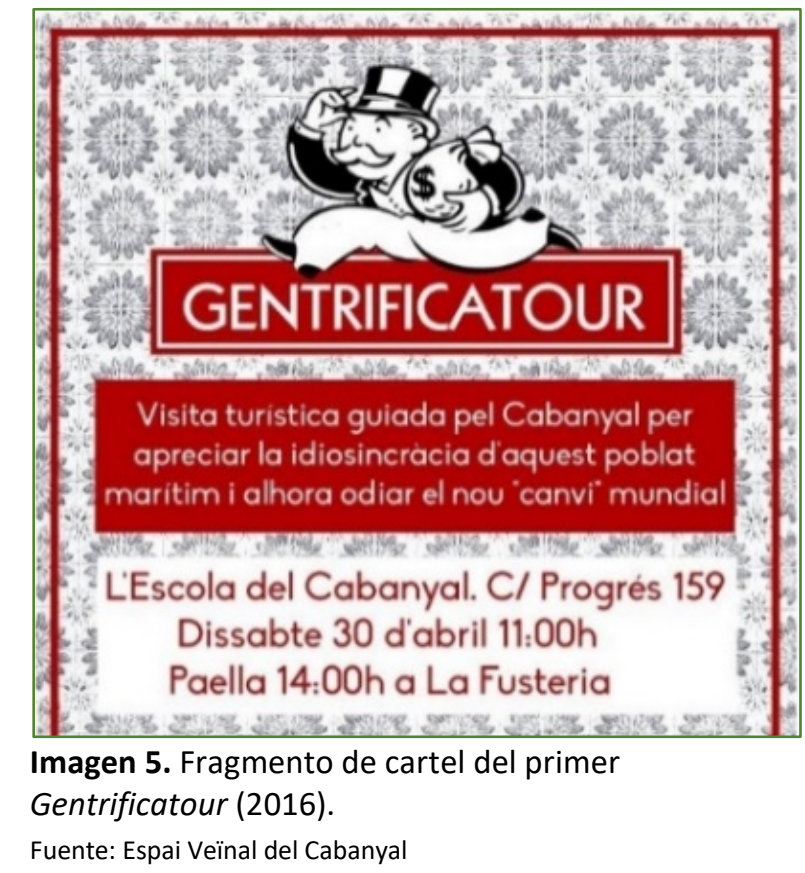

Un año después, en marzo de 2018, la presión vecinal paralizaba la compra de La Collectiva por un fondo de inversiones. En ese momento formaban parte de ella trece proyectos, entre ellos Brúfol o Millorem, asociaciones de intervención socioeducativa con

17 Un reportaje de The Guardian califica recientemente el Cabanyal como "10 of the coolest neighbourhoods in Europe" y señalan: "esta porción auténtica de la ciudad permanece sin ser descubierta por la mayoría de los turistas. Si bien hay un nuevo ambiente cosmopolita, la personalidad tradicional del barrio está siendo apreciada por los recién llegados, y las nuevas tiendas y bares que surgen en todas partes tienden a respetar y adaptar la arquitectura autóctona en lugar de reemplazarla" (08/02/2020).

18 https://www.facebook.com/mardamura/about/?ref=page_internal 
vecindad gitana y romá. Sin embargo, en marzo de 2019, La Col-lectiva fue finalmente comprada y en su comunicado de despedida señalaban:

"Esperamos que esta pérdida sirva al menos para alertar sobre estos procesos tanto a la sociedad valenciana como a los responsables políticos, cuya insuficiente acción es una de las causas de esta situación. Desde nuestras asociaciones y colectivos seguiremos trabajando por una ciudad inclusiva en la que todo el mundo tenga derecho a vivir, un modelo opuesto al que nos está obligando a cerrar La Col·lectiva" (21/03/2019).

Como se desprende de este fragmento, La Col·lectiva aspira a que, al menos, su cierre se convierta en un mensaje hacia la sociedad y los poderes públicos en el que denuncian que no pueden ejercer su derecho a la ciudad. Sin embargo, el año de 2019 había iniciado con la presentación del PEC. El nuevo plan municipal incluía la planificación de dos bloques de edificios en los huertos urbanos de Cabanyal Horta. Implicaría la destrucción de otro colectivo y de su densidad de redes vecinales tejidas en los últimos cinco años. A pesar de las más de mil alegaciones recibidas, el PEC, todavía en trámite, no ha modificado su intención de construcción en este jardín autogestionado. Una decisión paradójica teniendo en cuenta la cantidad de solares de titularidad pública diseminados por el barrio ${ }^{19}$ que, de nuevo, nos reenvía al avance de la mercantilización a través de espacios anticapitalistas y a estrategias de pacificación del lugar mediante la desposesión.

En septiembre de 2019 cerró sus puertas el CSOA La Fusteria después de casi diez años en activo en una antigua carpintería convertida en un lugar de sociabilidad mediante actividades reivindicativas: ciclos de cine sobre gentrificación, teatro político, jornadas, debates, etc. que, a menudo, traspasaban sus puertas para ocupar la calle desde la desobediencia. Incluimos un fragmento del diario de campo relativo a su cierre:

"Le pregunto a John cómo van en La Fusteria porque he leído una noticia en redes sociales, está 'amenazada con desaparecer'. Me explica que 'el banco malo' (Sareb) que poseía La Fusteria la ha vendido a un particular que quiere hacer apartamentos turísticos. El colectivo ha hablado con el nuevo propietario para negociar una salida sin denuncias y John me explica: 'no podemos resistir el espacio porque ya no tenemos fuerzas'. Me parece que la afirmación 'ya no tenemos fuerzas' condensa el significado de la gentrificación para estos movimientos. Añade: 'ya tenemos fecha para el desalojo pasivo'. 'Pasivo' porque no se opondrán de forma activa. Le pregunto cuándo es la fecha y me responde: 'el 31 de septiembre'. Su tono me parece de resignación y tristeza. A la suya se une la mía, me cuesta imaginar que La Fusteria no existirá en unos meses y no sé qué decirle. Al final le contesté algo que no me parece muy acertado: 'John, el 31 de septiembre no existe, será el 30 de septiembre'. Seguimos conversando sobre lo que quieren hacer de aquí a esa fecha en $L a$ Fusteria, incluida la campaña de denuncia contra la gentrificación" (Diario de campo, 25/01/2019).

En la siguiente actividad en La Fusteria, una obra de teatro del grupo Teatre Mariner, una pancarta colgaba del techo: "CSOA La Fusteria. 2011-2019. La Gentrificación nos expulsará el 31 de septiembre de 2019”. Estaba John, le digo que no recordó que ese día no existe, se sorprende de haberlo olvidado y que nadie lo haya comentado. Tal vez ahora 
podemos entender que no es un olvido. Esa fecha inexistente en el calendario condensa el deseo férreo de estos movimientos de seguir okupando el espacio y su rechazo a ser desalojados de La Fusteria. Una fecha imaginaria que simboliza que este proyecto, y otros posicionados frente a la ciudad neoliberal, no desaparecen, sino que se inscriben en la historia del barrio y en su topografía. Pasan a formar parte de la memoria de unos movimientos con poder acumulativo mediante acciones simbólicas y políticas. Se insertan en unos discursos, dirigidos a la sociedad y a los gobiernos, donde reclaman su derecho a la ciudad. Por último, también se desplazan, anclados en vecinas activistas que acumulan experiencias y saberes de resistencia frente a la acumulación por desposesión.

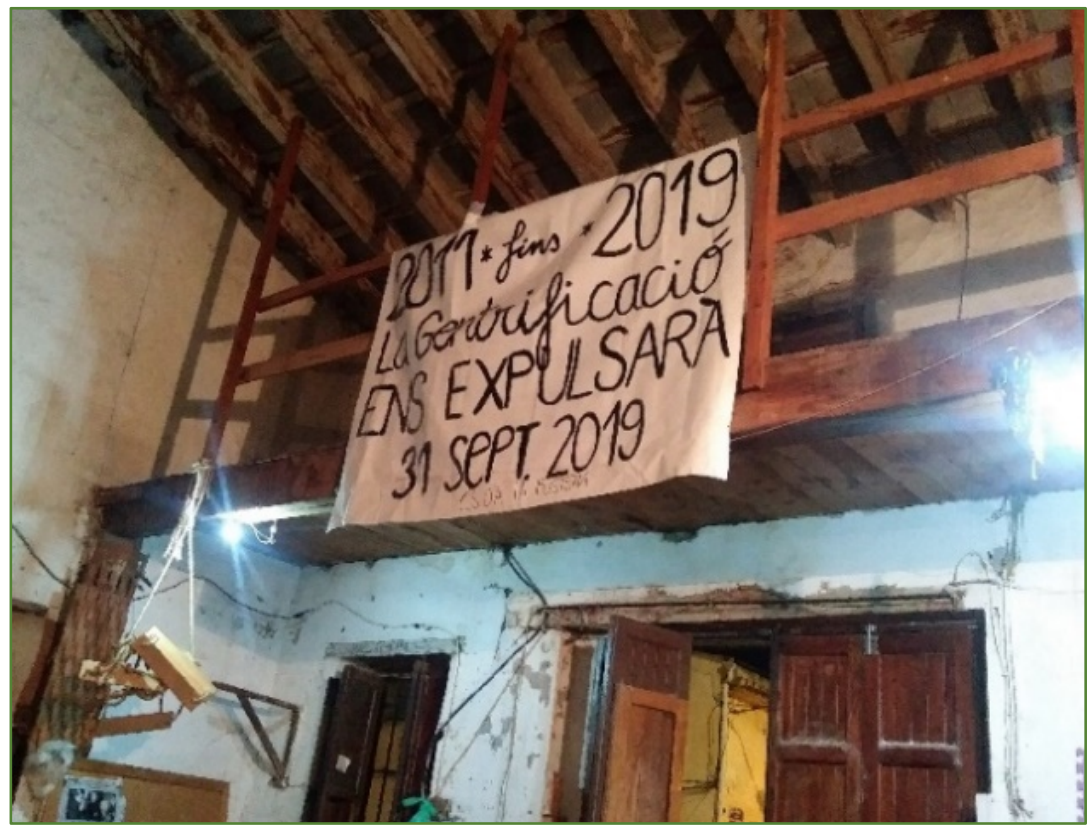

Imagen 6. "La gentrificación nos expulsará. 31 de septiembre 2019".

Fuente: Elaboración propia

\section{A modo de conclusión: la gentrificación de los movimientos urbanos frente a la ciudad neoliberal}

Más allá de la heterogeneidad de prácticas, discursos y saberes movilizados por movimientos urbanos para enfrentarse a la gentrificación, el análisis pretendía mostrar, sin una mirada dicotómica, que son actores profundamente afectados por esa gentrificación que combaten. La reflexión giraba en torno a las lógicas interrelacionadas de desplazamiento y desposesión para señalar sus efectos en los movimientos. Por un lado, a través de las trayectorias de sus miembros emergía el vaciado de una vecindad-activista atravesada por precariedades y desigualdades de clase social, género, edad y/o etnia. En ese sentido, afirmábamos a partir de lo observado en el trabajo de campo que estamos ante una gentrificación feminizada, juvenil y etnificada. Por otro lado, el desalojo de lugares colectivos mostraba que el urbanismo neoliberal necesita elementos con memoria y patrimonio singulares, como algunos "espacios liberados" por estos movimientos. Se expande a través de la expropiación 
de prácticas en los márgenes del capitalismo y, al mismo tiempo, consigue la pacificación del lugar. Esto concuerda con las investigaciones que señalan, en otras ciudades europeas y de América Latina, que los movimientos pueden ser cooptados en su vertiente artística-cultural y, al mismo tiempo, reprimidos en sus luchas por la vivienda (Shaw 2007; Novy y Colomb 2013; Janoschka, Sequera y Salinas 2014; Mayer 2016; Sorando y Ardura 2016). En el Cabanyal como en otros barrios, la gentrificación avanza con estrategias de higienización que expulsan prácticas y actores no deseados.

Desde este análisis nos referimos a la gentrificación de los movimientos antigentrificación para abarcar los desplazamientos y desposesiones simbólico-materiales de los movimientos urbanos frente a la ciudad neoliberal. Este fenómeno da lugar a una sustitución progresiva de actores que cuestionan de manera transgresiva las lógicas capitalistas. El Cabanyal podría ser leído como una metáfora local de la despolitización que persigue el urbanismo neoliberal a través de silenciar unas políticas y reactivar otras. Dicho de otro modo, este barrio se "repolitiza" con un modelo urbano en el que sólo tendrían cabida los proyectos que sustentan el capitalismo o que no lo enfrentan de forma subversiva.

A pesar de la gentrificación de los movimientos antigentrificación, hemos sostenido que no desaparecen, sino que reaccionan a esta dinámica con múltiples estrategias. Por una parte, para minimizar los efectos del desplazamiento de los participantes, éstos intentan mantener las redes tejidas. 0 bien se trasladan a los alrededores del Cabanyal para seguir vinculándose a sus colectivos, o bien se mudan a barrios obreros periféricos donde poner en práctica lo aprendido durante años de movilizaciones. Por otra parte, se enfrentan al desalojo de sus espacios mediante denuncias y protestas, alegaciones a los nuevos planes urbanísticos o rituales para anclarlos en la memoria colectiva frente al borrado de la historia local. Además, la gentrificación, como proceso inacabado y ambivalente, deja intersticios para algunas resistencias que logran mantenerse. En clave de futuro podemos mencionar los colectivos feministas que politizan lo urbano de forma creciente en los últimos años o la inclusión de proyectos, como Espai Veïnal, en redes suprabarriales bajo el lema "Valencia no está en venta".

La gentrificación también es un proceso ambiguo con contradicciones que, a veces, son aprovechadas por esta acción colectiva. En el Cabanyal se han valido de algunas oportunidades para crear laboratorios donde experimentar el derecho a la ciudad desde la desobediencia, al menos hasta que llegue la desposesión para acumular capital y pacificar el lugar. En ese sentido, la gentrificación personifica el neoliberalismo con la mezcla de la mercantilización de todos los ámbitos de la vida y la gestión disciplinaria de las consecuencias de la desposesión. En definitiva, la gentrificación de los movimientos urbanos no emerge sólo como consecuencia de la mercantilización, sino como condición para que la lógica de la acumulación siga avanzando. El desplazamiento y la desposesión de los movimientos frente a la ciudad neoliberal no son por tanto efectos colaterales, sino intrínsecos a ella. Las estrategias para estigmatizarlos ("radicales", "antisistemas") y castigarlos (sanciones económicas) buscan, además de su desplazamiento, su deslegitimación. Tal vez porque, al menos, consiguieron importunar en el avance de la revaloración del Cabanyal al reapropiase del espacio urbano como un lugar de sociabilidad y reivindicación, pero no de consumo. No podemos medir sus victorias sólo en función de los 
objetivos ideológicos y utópicos que se proponen. Serían más bien escasas si pensamos en su aspiración de "desgentrificar" el Cabanyal. Sin embargo, las contradicciones de este fenómeno complejo nos llevan a concluir que la desposesión material y simbólica de espacios, relatos y saberes de protesta también puede ser leída como expresión de los logros de estos movimientos urbanos para obstaculizar y resistir a la ciudad neoliberal.

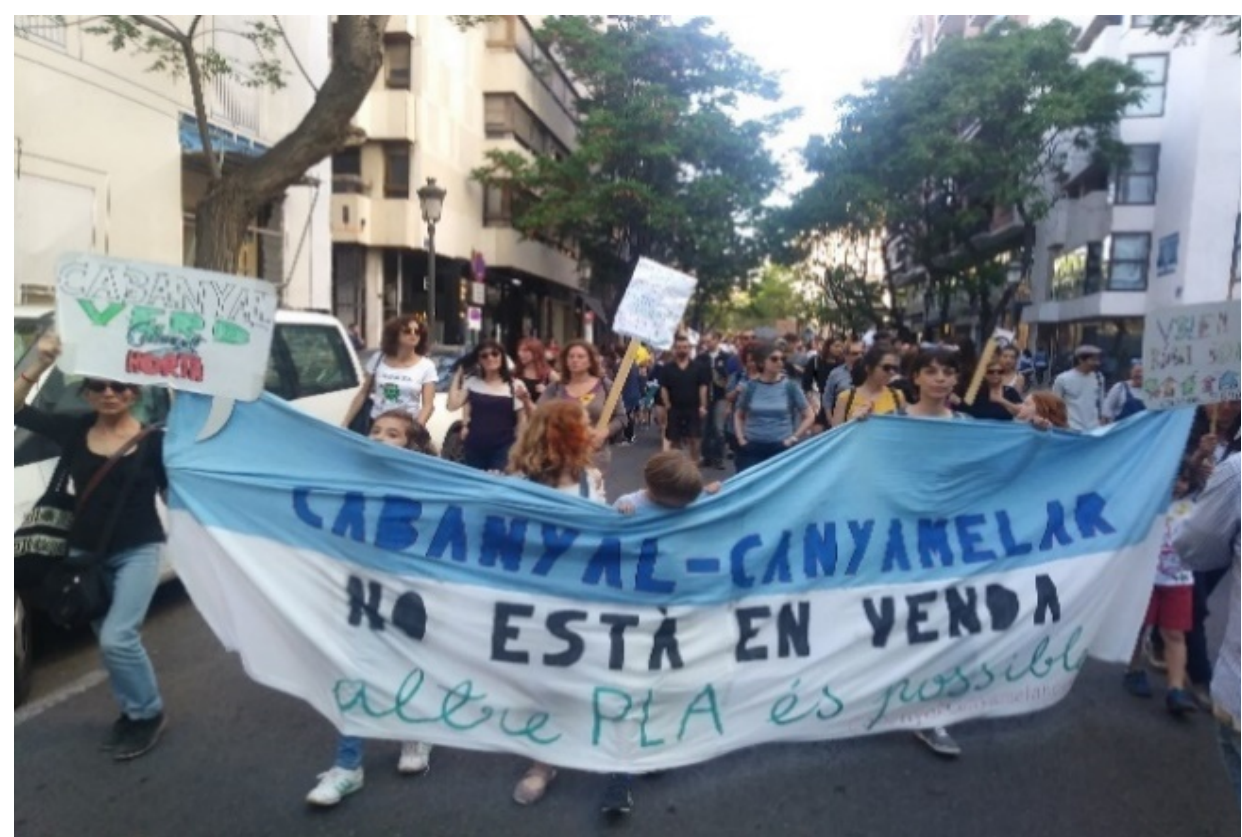

Imagen 7. Movimientos del Cabanyal en manifestación "Valencia no está en venta" (2019).

Fuente: Elaboración propia

\section{Bibliografía}

Albet, Abel, y Núria Benach. 2012. Doreen Massey. Un sentido global del lugar. Barcelona: Icaria.

Benach, Núria. 2016. “¿Ciudades en el mapa o en la guía turística? Venta de la ciudad y sentido del lugar". Revista CIDOB d'Afers Internacionals 113: 89-105. https://doi.org/10.24241/rcai.2016.113.2.89.

Benach, Núria, y Abel Albet. 2018. "La gentrificación como una estrategia global". Papers 60: 17-23.

Böhm, Steffen, Ana C. Dinerstein, y André Spicer. 2010. “(Im)possibilities of Autonomy: Social Movements in and beyond Capital, the State and Development". Social Movement Studies 9 (1): 17-32. https://doi.org/10.1080/14742830903442485.

Boira, Josep V. 1987. El Cabanyal-Canyameral. Valencia: Ayuntamiento de Valencia.

Boix, Rafael, Pau Rausell, y Raül Abeledo. 2017. "The Calatrava model: reflections on resilience and urban plasticity". European Planning Studies 25 (1): 29-47. https://doi.org/10.1080/09654313.2016.1257570.

Bonet, Jordi, y Marc Martí. 2008. "Los movimientos urbanos: de la identidad a la glocalidad”. Scripta Nova 12 (270). 
Castells, Manuel. 1986. La ciudad y las masas. Sociología de los movimientos sociales urbanos. Madrid: Alianza.

Cepeda-Másmela, Carolina. 2018. "Resistencias contra el neoliberalismo: una conceptualización de su ejercicio entre lo local y lo global". Relaciones Internacionales 39: 59-80.

Cruces, Francisco. 2006. Símbolos en la ciudad. Lecturas de antropología urbana. Madrid: UNED.

Cucó, Josepa. 2009. "Los movimientos urbanos en la ciudad de Valencia: contexto y caracterización”. Zainak 31: 529-49.

Cucó, Josepa, ed. 2013. La ciudad pervertida: una mirada sobre la Valencia global. Barcelona: Anthropos.

Cucó, Josepa. 2014. "En aras de la globalización neoliberal: los barrios del water front de Valencia”. Sociologia urbana e rurale 104: 12-28. https://doi.org/10.3280/SUR2014104002.

Day, Richard J.F. 2005. Gramsci is dead: Anarchist Currents in the Newest Social Movements. London: Pluto Press.

Del Valle, Teresa. 2000. "La organización del tiempo y del espacio: análisis feminista de la ciudad". Zainak 19: 53-60.

Diz, Carlos. 2018 "Tácticas del cuerpo: activismo y resistencia en la ciudad en crisis". Disparidades. Revista de Antropología 73 (1): 127-52.

Escobar, Arturo. 2010. Una minga para el postdesarrollo: lugar, medio ambiente y movimientos sociales en las transformaciones globales. Lima: Universidad Nacional Mayor de San Marcos.

Franquesa, Jaume. 2007. "Vaciar y llenar, o la lógica espacial de la neoliberalización". REIS 118 (1): 123-50. https://doi.org/10.2307/40184799.

Feixa, Carles, y Jordi Nofre, eds. 2013. \#GeneraciónIndignada. Topías y Utopías del 15 M. Lleida: Milenio.

Gaja, Fernando. 2000. "La ciutat de València en el segle XX". En Historia de la Ciudad. Recorrido histórico por la arquitectura y el urbanismo de la ciudad de Valencia, 21953. Valencia: COACV.

García, Beatriz. 2004. "Cultural policy and urban regeneration in Western European cities: lessons from experience, prospects for the future". Local Economy 19 (4): 312-26. https://doi.org/10.1080/0269094042000286828.

Glass, Ruth. 1964. "Introduction". En London: Aspects of Change, XIII-XLIII. London: MacGibbon and Kee.

Gradolí, Carmel, ed. 2015. "VaCabanyal. Análisis y diagnósticos”. http://vacabanyal.org/.

Graeber, David. 2009. Direct Action: An Ethnography. Oakland: CAK Press.

Hamel, Pierre, Henri Lustiger-Thaler, y Margit Mayer, eds. 2000. Urban Movements in a Globalising World. London: Routledge.

Harvey, David. 1978. "The urban process under capitalism: a framework for analysis". International Journal of Urban and Regional Research 2: 101-31. https://doi.org/10.1111/j.1468-2427.1978.tb00738.x. 
Harvey, David. 2006. "Neo-liberalism as creative destruction". Geografiska Annaler: Series B 88 (2): 145-58. https://doi.org/10.1111/j.0435-3684.2006.00211.x.

Harvey, David.. 2013. Ciudades rebeldes: del derecho de la ciudad a la revolución urbana. Madrid: Akal.

Iglesias, Mariela, Marc Martí-Costa, Joan Subirats, y Mariona Tomàs, eds. 2011. Politicas urbanas en España: Grandes ciudades, actores y gobiernos locales. Barcelona: Icaria.

Jacobs, Jane. 2011. Muerte y vida de las grandes ciudades. [1961]. Madrid: Capitán Swing.

Janoschka, Michael, Jorge Sequera, y Luis Salinas. 2014. "Gentrification in Spain and Latin America - a Critical Dialogue". International Journal of Urban and Regional Research 38 (4): 1234-65. https://doi.org/10.1111/1468-2427.12030.

Juris, Jeffrey S. 2010. "Reinventing the rose of fire: anarchism and the movements against corporate globalization in Barcelona”. Hitoria Actual Online 21: 143-55.

Lees, Loretta, Hyun Bang Shin, y Ernesto López-Morales. 2016. Planetary Gentrification. London: Polity Press.

Lefebvre, Henri. 1968. Le droit à la ville. Paris: Éditions Anthropos.

Logan, John R., y Harvey L. Molotch. 1987. Urban fortunes: The political economy of place. Berkeley-London: University of California Press.

Marcuse, Peter. 1985. "Gentrification, Abandonment, and Displacement: Connections, Causes, and Policy Responses in New York City". Washington University Journal of Urban and Contemporary Law 28: 195-240.

Martínez, Miguel A. 2007. "El Movimiento de Okupaciones: Contracultura urbana y dinámicas alter-globalización”. Revista de Estudios de Juventud 76: 225-43.

Massey, Doreen. 2012. "Un sentido global del lugar”. En Doreen Massey. Un sentido global del lugar, de Abel Albet y Núria Benach, 112-29. Barcelona: Icaria.

Mayer, Margit. 2012. "The 'right to the city' in urban social movements". En Cities for People, Not for Profit: Critical Urban Theory and the Right to the City, editado por Neil Brenner, Peter Marcuse, y Margit Mayer, 63-85. New York: Routledge.

Mompó, Eva. 2016. “Contra-narrativas y prácticas de resistencia en un conflicto urbano. Una respuesta autónoma desde El Cabanyal (Valencia)". En Congreso Internacional Contested Cities. Madrid: Contested Cities. http://contested-cities.net/workingpapers/autor/eva-mompo/.

Mompó, Eva. 2019. “'Por un barrio vivo y combativo'. Movimientos urbanos en búsqueda de autonomía desde el Cabanyal". Valencia: Universitat de València.

Novy, Johannes, y Claire Colomb. 2013. "Struggling for the right to the (creative) city in Berlin and Hamburg: new urban social movements, new 'spaces of hope'?" International Journal of Urban and Regional Research 37 (5): 1816-38. https://doi.org/10.1111/j.1468-2427.2012.01115.x

Rodó-de-Zárate, Maria. 2014. "Developing geographies of intersectionality with Relief Maps: reflections from youth research in Manresa, Catalonia". Gender, Place \& Culture 21 (8): 925-44. https://doi.org/10.1080/0966369X.2013.817974.

Romero, Joan. 2019. "Sobre las geografías del malestar en Europa”. Papeles de relaciones ecosociales y cambio global 147: 61-72. 
Ruiz, Miquel A., y Pedro García Pilán. 2013. “Disolución del lugar y espacios del miedo en el Cabanyal". En La ciudad pervertida: una mirada sobre la Valencia global, editado por Josepa Cucó, 67-92. Barcelona: Anthropos.

Sanchis, Antonio. 1997. Historia del Cabanyal. Poble Nou de la Mar. Valencia: Javier Boronat.

Sanchis, Antonio. 1998. Historia del Cabanyal. Siglo XX y el incierto futuro. Valencia: Javier Boronat.

Santamarina, Beatriz. 2009. "Cabanyal, cada vez más cerca. Del lugar al espacio como mercancía." Zainak. Cuadernos de Antropología-Etnografía 32: 915-31.

Santamarina, Beatriz. 2014. "El oficio de la resistencia. Salvem y Viu al Cabanyal como formas de contención del urbanismo neoliberal". Revista de Dialectología y Tradiciones Populares 69 (2): 305-26. https://doi.org/10.3989/rdtp.2014.02.003.

Santamarina, Beatriz, y Camila Del Mármol. 2017. "Ciudades creativas y pueblos con encanto: los nuevos procesos patrimoniales del siglo XXI". Disparidades. Revista de Antropología 72 (2): 359-77. https://doi.org/10.3989/rdtp.2017.02.003.

Santamarina, Beatriz, y Eva Mompó. 2018. “Tácticas de resistencia en la ciudad. Alternativas desde los movimientos urbanos en El Cabanyal (Valencia, España)". AIBR, Revista de $\begin{array}{llll}\text { Antropología } & \text { Iberoamericana } & \text { 381-405. }\end{array}$ https://doi.org/10.11156/aibr.130305.

Santamarina, Beatriz, y Eva Mompó. 2020. "La calle por bandera. Gramáticas, tropos y marcadores en los movimientos urbanos del Cabanyal (Valencia, España)". Revista de Antropología Social 29 (2): 155-71. https://doi.org/10.5209/raso.71670

Santos, Boaventura de Sousa. 2010. Descolonizar el saber, reinventar el poder. Montevideo: Ediciones Trilce.

Sassen, Saskia. 1991. The Global City. New York, London, Tokyo. Princeton: Princeton University Press.

Scheper-Hughes, Nancy. 1997. La muerte sin llanto. Violencia y vida cotidiana en Brasil. Barcelona: Ariel.

Schumpeter, Joseph A. 2003. Capitalism, Socialism and Democracy. [1942]. London: Routledge.

Scott, Allen J. 2014. "Beyond the creative city: cognitive-cultural capitalism and the new urbanism". $\quad$ Regional $\quad$ Studies $48 \quad$ (4): $465-78$. https://doi.org/10.1080/00343404.2014.891010.

Shaw, Kate. 2005. "The Place of Alternative Culture and the Politics of its Protection in Berlin, Amsterdam and Melbourne". Planning Theory \& Practice 6 (2): 149-69. https://doi.org/10.1080/14649350500136830

Slater, Tom. 2015. "La expulsión de las perspectivas críticas en la investigación sobre gentrificación". En El mercado contra la ciudad, editado por Observatorio Metropolitano de Madrid, 107-44. Madrid: Traficantes de Sueños.

Smith, Neil. 1979. "Toward a theory of gentrification: a back to the city movement by capital, not people". Journal of the American Planning Association 45 (4): 538-48. https://doi.org/10.1080/01944367908977002.

Smith, Neil. 1996. The new urban frontier: Gentrification and the Revanchist city. Londres: Routledge. 
Sorando, Daniel, y Álvaro Ardura. 2016. First we take Manhattan: la destrucción creativa de las ciudades. Madrid: Catarata.

Swyngedouw, Erik, Frank Moulaert, y Arantxa Rodriguez. 2002. "Neoliberal urbanization in Europe: large-scale urban development projects and the new urban policy". Antipode 34 (3): 542-77. https://doi.org/10.1111/1467-8330.00254.

Tarrow, Sidney. 1997. El poder en movimiento. Los movimientos sociales, la acción colectiva y la política. [1994]. Madrid: Alianza.

Torres, Francisco, Albert Moncusí, Miguel Monsell, y Yaiza Pérez. 2016. El vecindario romá, gitanos rumanos, y los inmigrantes que ejercen de aparcacoches en Valencia. Valencia: Ayuntamiento de Valencia.

Valentine, Gill. 2007. "Theorizing and Researching Intersectionality: A Challenge for Feminist Geography". The Professional Geographer 59 (1): 10-21. https://doi.org/10.1111/j.1467-9272.2007.00587.x.

Wacquant, Loïc. 2015. "Reubicar la gentrificación: clase trabajadora, ciencia y Estado en la reciente investigación urbana”. En El mercado contra la ciudad, editado por Observatorio Metropolitano de Madrid, 145-56. Madrid: Traficantes de Sueños.

Zibechi, Raúl. 2011. Territorios en resistencia: cartografía política de las periferias urbanas latinoamericanas. Madrid: Baladre.

(C) Copyright: Eva Mompó, 2021

(C) Copyright: Scripta Nova, 2021.

Ficha bibliográfica:

MOMPÓ, Eva. "Ya no tenemos fuerzas". La gentrificación de los movimientos antigentrificación: una reflexión etnográfica. Scripta Nova. Revista Electrónica de Geografía y Ciencias Sociales. Barcelona: Universitat de Barcelona, vol. 25, Núm. 2 (2021), p. 155-178 [ISSN: 1138-9788]

DOI: $10.1344 / \operatorname{sn} 2021.25 .32581$ 